\title{
10
}

\section{FROM EVALUATION OF JOINT PROGRAMMES TO JOINT EVALUATION OF SDGs-READY INTERVENTIONS}

\section{Lessons from the Joint GEF-UNDP Evaluation of the Small Grants Programme}

\section{Carlo Carugi and Heather Bryant}

\section{Introduction}

The signatories to the 2030 Agenda for Sustainable Development resolved not only "to free the human race from the tyranny of poverty and want" but also to "secure our planet" (UN 2015). The 17 Sustainable Development Goals (SDGs) that constitute the Agenda integrate and recognize the indivisibility of the three dimensions of sustainable development: the economic, social and environmental. At least three goals are considered to be "environmental", 39 of the targets are directly related to the environment (Elder and Olsen 2019) and 93 of the 244 indicators - spread across almost all goals - have an environmental dimension (UNEP 2019). However, while the SDGs have brought the social, the economic and the environmental closer to each other in discourse, development practice, monitoring and evaluation do not equally address or integrate these dimensions. For example, while approximately half of all SDG indicators are classified as Tier $1,{ }^{1}$ only $27 \%$ of the environment-related indicators are in this category. ${ }^{2}$ With respect to evaluation, Uitto (2019) observes that the profession has primarily focused on the human dimensions of development while neglecting the environmental, while Rowe (2019) points out that evaluations usually take a "single system perspective" where, for example, evaluations addressing conservation concerns in a natural system tend to be unconcerned with effects on the human system, and evaluations focused on a human system concern do not consider effects in the natural system.

Joint programming (where different agencies bring complementary expertise to address complex development problems) and joint evaluations (where different evaluation offices combine diverse skills to evaluate development interventions) offer opportunities to better integrate and understand the social, economic and environmental dimensions of development programming and results. In the UN system, joint programming has been encouraged since the beginning of the 
century, with the adoption of Guidelines on Joint Programming in 2003, and given new impetus through the creation of the Millennium Development Goals (MDGs) Achievement Fund which funded 130 joint programmes between 2007 and 2013 (UNDP 2014). Building upon the experience and lessons learned of the MDG Achievement Fund, the Sustainable Development Goals Fund was created, acting as a bridge in the transition from the MDGs to the SDGs, providing concrete experiences on how to achieve a sustainable and inclusive world post-2015 through integrated and multidimensional joint programmes. This fund represents a concrete response to SDG 17's call for strengthening the means of implementation and revitalizing the global partnership for sustainable development, implicitly promoting partnering in joint programmes.

In the first edition of this book (2014), Bodemann-Ostow and Gallego Piñero explored the opportunities and challenges of evaluating environment joint programmes, based on lessons from the MDG Achievement Fund. They analysed 28 evaluations of joint programmes under two funding windows that addressed climate issues: environment and climate change and water governance. The authors sought to draw lessons from the review to help evaluators and programme teams develop effective tools to evaluate joint programmes, discussing challenges but also benefits of evaluation processes. They noted that a central feature of the Fund's development programmes was the application of a multi-sectoral approach, based on the Fund's view of the MDGs not as a set of individual targets, but rather closely interconnected ones. The evaluations of the Fund's joint programmes thus considered, among others, whether a joint programme's objectives and overall design had been holistically designed. This meant, for example, in the environment and climate change and water governance thematic windows, that "issues of environmental infrastructure, entrepreneurship promotion and environmental education, for example, were considered jointly with capacity building, local empowerment and gender mainstreaming” (p. 257).

Bodemann-Ostow and Gallego Piñero found, among others, that the evaluation processes had significant implications for the programmes themselves, with "positive effects on programme cohesiveness, management and decision making, on programme partner coordination and on ownership and stakeholder commitment to programme objectives" (p. 270). They also highlighted common challenges the evaluators faced, such as the lack of cohesion between individual programme components to their overall objective, weak monitoring and evaluation frameworks, and the fact that geographic dispersion, time limitations and frequent national counterpart staff turnover created information gaps (pp. 273-274). These are challenges common to many programmes and their evaluations, whether joint or not.

The evaluations analysed by Bodemann-Ostow and Gallego Piñero were not "joint"; the evaluations were commissioned and managed by the Fund's Secretariat, and generally carried out by a single evaluator or teams of two. This chapter picks up where Bodemann-Ostow and Gallego Piñero left off and argues that joint evaluation, where diverse institutions bring together their corporate skills, data, technical knowledge, expertise and experience to the assessment of the social, economic 
and environmental dimensions of development initiatives, is well suited to assess development interventions in the SDG era. Joint evaluation however also brings its own challenges. Lessons from a joint evaluation by the Independent Evaluation Offices (IEOs) of the Global Environment Facility (GEF) and the United Nations Development Programme (UNDP) of the Small Grants Programme (SGP) point to both advantages and potential pitfalls of such an approach.

This chapter begins with an overview of joint evaluations and some of the lessons learned, followed by a short reflection on the SDGs and joint evaluation. Then follows an introduction to the joint evaluation of the SGP and a discussion of the lessons from this evaluation, including both practical aspects of carrying out a joint evaluation and reflections on how this evaluation examined multiple dimensions of the SGP and on potential lessons for future "two system" evaluations.

\section{Overview of joint evaluations}

Joint evaluations are not a recent phenomenon. The OECD DAC evaluation network considered them "at almost every meeting" in the 1980s (OECD-DAC 2013: 17). In the 1990s, members of this evaluation network undertook a number of important joint evaluations, one example of which is an evaluation of the international response to conflict and genocide in Rwanda, led by Denmark with several OECD members and UN Agency partners (OECD-DAC 2005). In the late 1990s, the DAC Working Party on Aid Evaluation began focusing on joint sector evaluations in selected developing countries. The group observed that "in the medium term this will be particularly relevant for monitoring progress towards achieving the goals of 'Shaping the 21st Century'" (OECD-DAC 1998), an OECD-DAC precursor to the MDGs. In 2000, the MDGs were adopted, and in 2006, the UN Secretary General convened a panel on UN system-wide coherence. In his remarks on the panel's report, he stated that, "It will be essential that we swiftly modernize and achieve full compatibility on processes for resource planning, human resources, common services and evaluation, as these are important drivers of coherence in the United Nations system (UN 2006, para.17)." As discussed in Bodemann-Ostow and Gallego Piñero, evaluation of joint programmes was an important component of the MDG Achievement Fund.

Joint evaluations are not without their challenges, and the OECD DAC observed in 2013, "a bit of a backlash to joint evaluations" (OECD-DAC 2013: 24). Data on UNDP evaluations also shows that the number of joint evaluations peaked in 2013 and then decreased (Carugi and Bryant 2019). Various papers published over the past several years have highlighted benefits and challenges of joint evaluations. On the positive side, several of them emphasize the importance of joint evaluations in a context of common, multidimensional development goals that can only be achieved through partnerships (OECDDAC n.d.) with specific reference to the MDGs (Feinstein and Ingram 2003; OECD-DAC 2005; UNEG 2014). Joint evaluations allow expansion of the scope 
and the number of evaluation questions that can be addressed with combined resources (OECD-DAC n.d.). They may also "facilitate a sense of the bigger picture within which a programme or set of joint activities is situated" (UNEG 2014: 24). Joint arrangements have the potential to yield higher quality, more credible evaluations (Feinstein and Ingram 2003; OECD-DAC n.d.; OECDDAC 2005; UNEG 2014). Analyses, findings, conclusions and recommendations of joint evaluations are based on broader knowledge and a wider range of inputs and contributions (OECD-DAC 2005). They also benefit from joint rather than individual scrutiny and quality assessment procedures (UNEG, 2014). There is a greater likelihood that a variety of methods for data collection and analysis will be used in a joint evaluation, as different agencies may have different types of data available, and experiences using different approaches (OECD-DAC 2005; UNEG 2014). Similarly, interviews can be more easily conducted with a wider range of stakeholders, allowing for better triangulation (UNEG 2014). Several of these sources emphasize that joint evaluations typically carry more weight and are less easy to ignore than a single agency evaluation as they reflect the views of multiple partners (Feinstein and Ingram 2003; OECD-DAC 2005; UNEG 2014). It is also argued that joint evaluations reduce transaction costs for the evaluand and the stakeholders consulted, as the total number of missions with a joint evaluation is less than if each donor carried out its own evaluation (Feinstein and Ingram 2003; OECD-DAC 2005; UNEG 2014). Joint evaluations also reduce multiple messages, and the risk of conveying conflicting evaluation messages to partner countries (OECD-DAC 2005; UNEG 2014). Joint evaluations result in a reduced financial burden through cost sharing (Feinstein and Ingram 2003; OECD-DAC n.d.). Another benefit, it is also postulated, is that joint evaluations foster mutual capacity development and peer learning, as agencies learn from each other and share evaluation techniques, and partners come to understand better the different perspectives, mandates and approaches of each of the institutions involved (Feinstein and Ingram 2003; OECD-DAC n.d.; OECD-DAC 2005; UNEG 2014).

However, these papers also highlight a number of challenges with joint evaluations. Developing comprehensive and yet manageable terms of reference that meet each partner's needs may take time and require compromises (OECD-DAC n.d.; SADEV 2008; UNEG 2014). Joint evaluations are typically characterized by complex management, communications and governance arrangements, and generally require more time to carry out, which in turn may result in being more costly than individual agency evaluations (Feinstein and Ingram 2003; OECDDAC n.d.; OECD-DAC 2005; SADEV 2008; UNEG 2014). Methodologies can also become an area of contention and reaching agreements on methods may also extend the time frame of the preparatory phase (OECD-DAC 2005; SADEV 2008). Other challenges may include power differentials between partners and different needs and accountability requirements of the partner organizations (UNEG 2014). 


\section{SDGs and joint evaluation}

These reflections on the advantages and disadvantages of joint evaluations are relevant as the adoption of the SDGs in 2015 is leading to renewed interest in joint evaluations. First, the 2030 Agenda gives greater recognition to evaluation than did the Millennium Declaration. Paragraph 74 of the 2030 Agenda states that "follow-up and review processes at all levels will be guided by the following principles: ... they will be rigorous and based on evidence, informed by country led evaluations..." (UN General Assembly 2015). Second, new commitments such as the "funding compact" between Member States and entities of the UN Sustainable Development Group highlight that

the objective of pursuing joint activities, notably in the areas of analytical work and the formulation of operational support and policy options for acceleration and evaluation of progress towards the achievement of the Sustainable Development Goals, is to ensure that United Nations support is coherent and efficient across economic, social and environmental issues (UN 2019, para. 30).

And third, the UN Secretary is establishing a dedicated capacity to coordinate system-wide evaluations and advance shared learning and accountability for the 2030 Agenda (UN 2020). This new office will be tasked with conducting evaluations designed to complement the evaluative work of UN entities, focusing on "joint activities that cannot adequately be addressed through other existing UN accountability mechanisms" (UN 2020, para 111). Joint evaluations serve an intermediary purpose - addressing issues that can be better addressed together rather than by a single evaluation entity, but which may not require a system-wide evaluation. The Evaluation Cooperation Group (ECG) (whose members are multi-lateral development banks) is also giving increased attention to joint evaluations, discussed at the ECG Fall 2018 and Spring 2020 meetings. During the last discussion, joint evaluations were proposed among the ideas for future collaboration on upcoming priorities in response to the Covid-19 pandemic crisis, a global public health issue that is strongly related to environment and socio-economic interlinkages. The UN Evaluation Group, equally cognizant of the burdens multiple evaluations may pose on programme countries, is seeking ways to increase joint evaluations and other forms of evaluation cooperation between the UN evaluation units.

To understand progress in the context of the SDGs, evaluation needs to go beyond examining results in a single dimension and carefully look at trade-offs and synergies between the economic, social and environmental dimensions to assess how different outcomes can be valued. In this line, Uitto (2019) highlights the importance of mixed methods approaches and the need for interdisciplinary teams to evaluate at the nexus of the environment and development. Similarly, Rowe (2019) argues for "sustainability-ready evaluation" that addresses coupled human and natural systems, recommending that expertise from "both systems" be present in an evaluation team. 
One way to bring the interdisciplinarity needed to assess the integrated nature of the SDGs is for specialized institutions to partner in joint evaluations, each contributing their respective corporate skills and technical knowledge as well as their institutional expertise, data and experience on the issues under scrutiny. The discussion on partnering for addressing the integrated nature of the SDGs is particularly relevant to the GEF, one of the few international institutions based on partnership. A special challenge is posed in adequately monitoring and evaluating the achievements of the GEF, accounting for the activities of all partners in a consistent and coherent manner.

In 2015, the IEOs of the GEF and the UNDP carried out a joint evaluation of a unique programme, the SGP. While the evaluation itself pre-dated the SDGs, the experiences not only nourish the ongoing discussion of challenges and opportunities of joint evaluations but also bring new insights with respect to the need to integrate multiple dimensions into evaluations in the context of the SDGs.

\section{The joint GEF-UNDP evaluation of the Small Grants Programme}

The GEF is a financial mechanism for international cooperation that addresses global environmental concerns while supporting national sustainable development initiatives. The GEF operates through a large partnership involving 183 countries, 18 agencies and a large network of civil society organizations and private sector entities. The GEF created the SGP in 1992 with the aim of developing community-led and -owned strategies and technologies for reducing threats to the global environment while addressing livelihood challenges. Implemented by UNDP, the SGP awards small grants - up to a maximum of $\$ 50,000$ - to needy communities to support the use of practices and technologies that benefit the global environment. Since its start up, the SGP has provided about 23,990 small grants with a total of $\$ 653$ million in grants (as of June 2019; GEF IEO and UNDP IEO 2020) to communities in more than 125 countries. The SGP cannot be considered a joint programme as it is implemented by only one agency, the UNDP. However, it incorporates the social, economic with the environmental at the local level, in full alignment with the SDG philosophy. To note, UNDP is the largest GEF Agency in terms of both number of projects and funding. UNDP is also one of the very first three GEF implementing Agencies and has been implementing the SGP since 1992.

The SGP has been jointly evaluated by the IEOs of the GEF and UNDP twice, in 2008 (GEF IEO and UNDP IEO 2008) and in 2015 (GEF IEO and UNDP IEO 2016). The 2008 joint SGP evaluation was an important milestone for the SGP. Overall, the evaluation found that the SGP is a cost-effective way for the GEF to generate global environmental benefits while addressing country priorities and responding to the needs of local populations. It also found that the SGP management model had reached its limits and was not suitable for a new phase of growth: the SGP governance and audit procedures needed to be strengthened. The 2015 joint SGP evaluation assessed the extent to which the most important recommendations from the 2008 evaluation had been implemented and the extent to which 
these recommendations and Council decisions remained pertinent. The evaluation also reported on the SGP's current role and results in terms of achieving global environmental benefits while addressing livelihoods, poverty, and gender equality; broader adoption of grant-level results; the SGP's strategic positioning; and monitoring and evaluation.

\section{Lessons from the joint evaluation of the SGP}

Experiences from the recent Joint GEF-UNDP evaluation of the SGP further illustrate many of both main advantages and challenges of joint evaluations. Lessons from this experience add to the lessons provided by Bodemann-Ostow and Gallego Piñero on evaluation of MDG-funded joint programmes. The evaluations of MDGFund joint programmes, often conducted by one consultant, did not benefit from the full spectrum of advantages inherent to joint evaluations such as the Joint GEFUNDP Evaluation of the SGP.

The following discusses the lessons learned from conducting this joint evaluation in the approximate order encountered in the evaluation process. First, practical and often challenging aspects like partnership arrangements, timing and management structure are described. More substantive aspects follow, including scope, methods and analysis, where the advantages and benefits of joint evaluations become more apparent.

\section{\# 1 Deciding on a joint evaluation}

The decision to carry out a joint evaluation is made within a political or institutional context. In the case of the SGP, the decision to conduct a joint evaluation was straightforward. The GEF funds the SGP, and UNDP implements it, making the two institutions natural partners for a joint evaluation. Both the UNDP and GEF evaluation offices are independent and have considerable scope in determining their work plans. A precedent had been set with the 2008 joint evaluation. For the two institutions, this specific context was conducive to the decision of conducting a joint evaluation.

Moving forward, the decision to undertake a joint evaluation may also be informed by Rowe's call for SDGs-ready, two-system evaluations, where the necessary capacities to assess the socio-economic and its interlinkages with the environmental are brought in by the participating institutions. Nevertheless, there are practical challenges: while partnering to carry out a joint evaluation may be an ideal way to approach "two system" evaluations, the programming and/or financial cycles of each participating institution do not always coincide; and timing an evaluation to meet the different institutional needs can be a challenge, as discussed below.

\section{\#2 Partnership arrangements}

The SGP experience suggests that institutions working as equal partners enhance joint evaluation success. It has been observed that there are often power differentials at play in joint evaluations, where one agency may end up dominating the 
evaluation process, either because it has invested more funding, has a stronger position in the management structure or because it has an agenda it wishes to pursue (UNEG 2014). The last point is particularly important. The political dimension can be a strong derailing force in any evaluation, and joint evaluations are no exception. For example, one institution may be seeking to terminate or exit from a programme, while the other may wish to continue. In such cases, the independent nature of the evaluation function within each institution mitigates such political interferences by bringing partnering agencies to the table together and reiterating the need to maintain focus on evidence-based responses to evaluation questions.

The SGP evaluation was carried out by the two IEOs as equal partners. The different mandates of the two institutions, development for UNDP and environment for the GEF, did mean the two had slightly different interests in the evaluation. This led to significant debates during the evaluation (see below on the scope of the evaluation), but these were debates between equal partners. Looking forward, the SGP experience - where the GEF and UNDP offices ensured both the environmental and the human dimensions of the evaluation were given appropriate weightage - suggests equal partner arrangements may help achieve balance and synergy when evaluating interventions in a two-system approach.

Partnership for joint evaluations includes agreeing on financial arrangements. A success factor of this joint evaluation - of potential interest to practitioners if not specific to the SDGs context or the question of two-system evaluations - was the approach adopted to co-financing. This is important in consideration of the fact that not only the share of co-financing from each participating institution but also the funding management modalities may influence the power dynamics in a joint evaluation. The joint SGP evaluation was co-financed by the IEOs of GEF and UNDP in equal shares, and by the SGP itself, from the SGP budget allocated for an Operation Phase 5 terminal evaluation. A key aspect of the co-financing for the evaluation was that the two offices agreed to share costs equally while avoiding complicated fund transfers between two institutions, each with its own financial, administrative and operational rules and procedures. The budget for the evaluation was designed with each institution taking responsibility for the funding of different components, with regular consultation to ensure the cost split remained equal. The trust built through the previous experience of joint work by the two offices facilitated the budget sharing arrangement.

\section{\#3 Timing}

Following the decision to conduct a joint evaluation and establishment of adequate partnership arrangements, the next practical consideration for a successful joint evaluation is timing. Timing is important in several respects. First, the evaluation process may be influenced by different reporting time frames of partnering institutions. In the case of the Joint Evaluation of the SGP, the timing of the evaluation was dictated by institutional programming time frames, rather than the state of the programme implementation or its results. More specifically, timing considerations 
led to a decision to conduct the evaluation in two phases. The first phase served the GEF IEO's need for information on the adoption and implementation of the 2008 recommendations within a fairly short time frame in order to contribute to the Fifth Overall Performance Study of the GEF (OPS5). The second phase was an opportunity to build on the first phase findings by addressing additional issues at the heart of the UNDP mandate, particularly related to livelihoods, poverty reduction and gender/inclusion. In practice, opportunities for a joint evaluation should be seized whenever possible and the evaluation process adapted as needed to meet organizational requirements.

A second aspect of timing is the length of time required to complete an evaluation. Joint evaluations typically take longer than a single-agency evaluation, and the SGP evaluation was no exception. The data collection and analysis phases (six months from approval of the terms of reference to submission of the draft report to the evaluation's joint steering committee) were no different than they would have been in a single agency evaluation, but convening the steering committee to review the drafts and agree on issues, followed by finalization of the report and obtention of final approval of the report by the steering committee took four months in the first phase, and seven months in the second phase, considerably longer than the usual time to finalize a single agency report. With reference to the SDG context and multi-sectoral interventions, the extended time line of joint evaluations as referenced in the literature and as experienced in the present case may present challenges to relevance and use of the final evaluation results, as conditions and interactions between dimensions are constantly changing on the ground.

A third element of timing that should be considered when looking at evaluations covering both human and environmental systems is the different time scales for environmental (usually long term), social and human development (shorter term) outcomes to materialize and become observable (Uitto 2019). For example, evidence from recent GEF IEO evaluations indicates that a lag time of 4.5-5.5 years was an important inflection point at which impacts of land degradation projects were observed to be larger in magnitude (GEF IEO 2016). To garner and maintain people's support for these initiatives, they are often accompanied by shorter-term livelihoods interventions. In the case of the SGP evaluation, given the nature of the small grant projects, it was often possible to observe initial changes in the natural environment (e.g. new plantings in a reforestation project or waste management improvements in villages) as well as in new socio-economic arrangements, such formations of cooperatives that not only engaged in conservation activities but also undertook income generating activities to provide economic benefits in the short term.

\section{\#4 Management structure}

Designing an appropriate management structure and developing adequate communication mechanisms are important for successful implementation of a joint evaluation. Joint evaluations have typically been characterized by complex 
management and governance arrangements. This was also the case of the present joint evaluation, with a three-tier management structure, including a top-heavy apex body. The challenges of the structure were partially mitigated by the communication strategies adopted by the evaluation managers. The management architecture and roles and responsibilities included a Steering Committee, a Management Team and an Evaluation team. The Steering Committee was co-chaired by the two offices' directors and included senior staff members from each office. The Committee proved to be an unwieldy decision-making forum, the convening of which required careful coordination of the members' respective busy agendas to avoid delays.

The Management Team, formed by two evaluation co-managers took care of the selection, hiring and supervision of consultants in accordance to mutually agreed Terms of Reference and institutional procedures; coordinated the evaluation activities carried out by both offices, quality-controlled evaluation deliverables and processes; and ensured the timely delivery of evaluation products. The quality of the collaboration between co-managers was key to the success of the joint SGP evaluation. Frequent communication, including short chats over Skype on specific issues significantly contributed to effective co-management.

The Evaluation Team included the management team complemented by one lead consultant, nine regional or national consultants and research assistants from both UNDP and GEF evaluation offices assigned to the evaluation. In addition to a long and diversified experience in evaluation (including joint evaluation), both evaluation co-managers had complementary skill sets. The UNDP IEO task manager has experience in poverty, livelihoods, gender and inequalities; the GEF IEO task manager in environment, natural resource management, and sustainable development. The lead consultant was an expert in evaluation and climate change.

The SGP evaluation structure did not include an Evaluation Reference Group, which was a feature of the joint programme evaluations discussed in BodemannOstow and Gallego Piñero, where representatives from each of the participating UN agencies and their national counterparts came together. Given the multi-layer management structure of the SGP evaluation, the addition of another formal mechanism would have been a burden. Key is ensuring that the management structure and evaluation process foster ownership and learning: at the country level, the MDG-Fund evaluation reference groups gave government counterparts a voice in the evaluation process (Bodemann-Ostow and Gallego Piñero 2014:24). In the case of the SGP evaluation, ad hoc briefing sessions were held with key corporate level stakeholders to gather feedback and strengthen ownership of the recommendations before the evaluation report was finalized.

\section{\#5 Scope}

Determining the scope of an evaluation - balancing the potential interest in answering a wide range of questions with the available resources - is critical for any evaluation. One of the main benefits of joint evaluations cited in the literature is the potential to broaden the scope and the number of questions to be answered given 
combined resources, provided it is kept at a manageable level. This is of particular interest if one is seeking to conduct a "two-system" evaluation, where there will necessarily be questions on both the environmental and the human spheres.

This was reaffirmed with the SGP evaluation, where the scope was broader than it might have been had only one agency conducted the evaluation. The 2015 evaluation broadened the scope beyond that of the 2008 evaluation, to not only examine environmental benefits but to include a more in-depth look at SGP's role in improving livelihoods, reducing poverty and contributing to gender equality and women's empowerment. Thus, the evaluation looked not only at the environmental but also at the interactions between the environmental, social and economic, the three dimensions at the heart of the 2030 Agenda.

Agreeing on the scope in the context of a two-system evaluation may generate debate. In the case of the SGP evaluation, expanding the scope beyond environmental considerations sparked numerous debates throughout the conduct of the evaluation. One reason was that different programme and evaluation stakeholders had differing interests. For example, the SGP programme manager (UNDP) saw one of the values of the programme as its ability to "reach the most vulnerable", whereas many environment specialists and GEF stakeholders challenged the claim, some arguing that it is virtually impossible to work with the most vulnerable as they do not have the necessary capacities to engage in development initiatives or are themselves a threat to the environmental benefits the programme seeks to secure. Some GEF stakeholders questioned UNDP's interest in examining SGP's socio-economic benefits in detail. The relevance of these questions and tensions is illustrated by the fact that one of the evaluation recommendations refers to the need to clarify the SGP's long-term vision, including the balance between global environmental benefits and socio-economic objectives.

A risk of joint evaluations with their potentially broader scope is however that the number of evaluation questions becomes unmanageable, as each agency has its own requirements, needs and interests. Again, this risk may be particularly relevant to two-system evaluations. In the case of the SGP evaluation, the scope was overly ambitious in the beginning. For example, the original terms of reference included a key question for the second phase of the evaluation, asking, to what extent the SGP, through its work with non-governmental and civil society organizations alike, facilitated civic engagement in the local and/or national policy arena, especially in post-conflict and fragile states. UNDP was interested in this aspect of the programme, given its mandate on governance and peacebuilding issues (which, in terms of the five "Ps" of the 2030 Agenda, would have added "peace" to the elements of "people, planet and prosperity" already captured by the focus on the social, environmental and economic aspects of SGP). However, the question was not of primary interest to GEF, and the evaluation management team also came to realize that there was a need to narrow the scope of the second phase of the evaluation, given resource constraints. Thus, maintaining the dual focus on environmental and socio-economic benefits required choices on the extent to which the latter could be addressed. 


\section{\#6 Multidimensional analysis}

Another feature and important benefit of this joint evaluation was the strengthened multidimensional analysis, composed of environmental and socio-economic research issues which drew on the strengths of the two partner evaluation offices highlighted earlier and which illustrates the interest of joint evaluations in the SDGs context. The GEF aims at achieving global environmental benefits. While not directly targeting socio-economic co-benefits, it welcomes when the initiatives it supports manage to achieve them too. UNDP focuses more on poverty reduction, livelihoods and gender, while the environment is a theme that cuts across UNDP's main strategic and operational pillars. The mandates of the two organizations overlap, but they are not identical, which can lead to differences in approach or emphases to programming, and by extension, to evaluation (Uitto, 2016). This joint evaluation however, in terms of evaluation purpose, objectives and key questions, was designed with a high degree of complementarity. Gender equality and livelihoods are both components of the SDG sustainability and resilience principles. The 2015 evaluation added a stronger emphasis on livelihoods, poverty reduction and gender results than the 2008 evaluation.

\section{\#7 Methods and tools}

Uitto (2019) argues that in most cases, a mixed methods approach is needed for sustainable development evaluation, with methods that capture changes in both the natural and human systems, further stating that "interdisciplinary teams are the gold standard" (p. 52). Earlier discussions on advantages of joint evaluations point to the potential for methodology development and the use of a greater variety of methods for data collection and analysis (UNEG 2014) brought to the table by the partner agencies. In the case of the SGP joint evaluation, many of the evaluation methods and tools were built upon and adapted from the ones developed and used in the 2008 joint evaluation. The team modified these tools to align with the new evaluation questions. New tools were also introduced. For example, 12 country studies were conducted, with field verification of 144 small grants projects. The team used the same tool that had been developed for the 2008 joint evaluation to assess grant project effectiveness in terms of economic benefits (also allowing for comparison with the 2008 evaluation results). Inspired by UNDP's "gender marker", the team developed new rating tools to assess the contributions of the grant projects to gender equality and women's empowerment as well as to the reduction of poverty, inequality and exclusion, allowing for more in-depth analysis of these aspects. More generally, data were collected through several additional complementary methods and tools: a global online survey reaching out to almost 2500 programme country stakeholders; an in-depth literature review of SGP documentation at all levels, from global to national; a meta-analysis of 30 randomly selected SGP country programme strategies and 50 evaluations covering SGP interventions; a portfolio review of performance and financial data for 18,000 small grant projects; and 
several key stakeholder interviews and focus groups at central level as well as in the countries visited during the evaluations. These tools generated a huge amount of both quantitative and qualitative data that could be used for generating solidly triangulated findings using techniques developed by the GEF team (Carugi, 2016) in response to each evaluation question.

This joint evaluation benefited from complementarity of skills and professional experience from UNDP - stronger than GEF in gender and livelihoods - and from the GEF, strong in environment. In addition to this complementarity, the experience offered an opportunity for peer learning, confirming one of the most common benefits of joint evaluations reported in the literature. Each component was designed together bringing diverse experience to bear on each section. The multidimensional analysis improved as a result, fitting perfectly to the nature of the evaluand, a global programme tasked with achieving both environmental and socioeconomic benefits at the local level. In other words, the nature of the SGP calls for this kind of integrated analysis, which makes this experience informative in the context of the discussion on joint evaluation for the SDG 2030 Agenda.

\section{\#8 Reducing multiple messages while multiplying use}

Recognized advantages of joint evaluations also include the potential for reducing multiple (and potentially conflicting) messages and broadened ownership of findings and recommendations (UNEG, 2014). The joint evaluation of the SGP examined several strategic and controversial (within the SGP universe) questions and, after extensive consultations including presentations of preliminary findings and recommendations to stakeholders, provided a single set of messages to both the GEF and its Council and UNDP (and by extension its Executive Board). This also contributed to evaluation use. The joint SGP evaluation led to structural changes in both organizations, a clear benefit. The evaluation recommended revitalization of the global SGP Steering Committee as a forum to provide high-level strategic direction and clarity of purpose to the programme, for example in terms of balancing the contributions to global environmental benefits and to other socio-economic benefits, which is central to SDGs' call for attention to dual-systems thinking in sustainable development interventions. Revitalization of the Global SGP Steering Committee also addresses the political/balance of power dimension related to two partnering institutions with complementary yet very diverse aims - the environmental and the human - both in terms of time (short vs long term) as well as scale (global vs local). The GEF Council, to which the GEF IEO reports directly, issued a corresponding decision addressed to the GEF Secretariat. UNDP also adopted recommendations regarding management of different SGP country programmes at different levels of maturity within a single unit to ensure coherence. Had the evaluation not been joint, detailed recommendations may not have been made to both institutions at the highest level. For example, UNDP alone could not have made recommendations to the GEF Council, and the GEF ensured that recommendations 
related to global environmental benefits were included, which might not have been the case had UNDP undertaken the evaluation by itself.

Looking at this in a broader context, the 2030 Agenda emphasizes the importance of multi-stakeholder partnerships to support achievement of the SDGs. Joint evaluations can facilitate, as did the SGP evaluation, formulation of common messages to stakeholders working in different "systems", the environmental and human, with the potential to lead to meaningful change.

\section{Conclusions}

Bodemann-Ostow and Gallego Piñero (2014), in their chapter in the first edition of this book, sought to draw lessons to help evaluators and programme teams develop effective tools to evaluate joint programmes, discussing challenges but also benefits of evaluation processes for improved programme coherence and results. This chapter has broadened the discussion on these opportunities and challenges to look at joint evaluations in the new context of the SDGs, where the social, the economic and the environmental have been brought closer together in development discourse.

Joint evaluations have been the subject of several guides and analyses over the past two decades (Feinstein and Ingram 2003; OECD-DAC n.d.; OECD-DAC 2005; SADEV 2008; OECD-DAC 2013; UNEG 2014), producing many lessons in terms of advantages and disadvantages as well as "do's and don'ts". Many of these were confirmed by the 2015 SGP evaluation discussed in this chapter. Joint evaluations have seen highs and lows over the years, with a backlash and resistance to these evaluations due to high transaction costs and heavy coordination requirements observed in the period leading up to 2015. The year 2015, however, represented a shift in the international development agenda with the adoption of the SDGs. The implications of the SDGs for multi-stakeholder approaches and integrated programming need to be incorporated into the evaluation agenda. As argued by Uitto (2019) and others, despite the increasing awareness of environmental threats to ecosystems that support human life and society, the evaluation profession has focused primarily on the socio-economic dimensions of development. This chapter has illustrated that joint evaluations - despite their challenges - offer significant advantages that can lead to important institutional and strategic changes with a view to strengthening development results in both the human and environmental spheres.

The literature and the 2015 SGP evaluation have shown that, for example, joint evaluations are suited when all institutions involved have a stake in the scope covered, provided the scope remains sufficiently delimited so that the key evaluation questions are kept to a manageable number. The temptation to add evaluation questions is likely to increase when looking at multiple dimensions - the environmental, the social and the economic - and thus must be carefully managed. Institutional arrangements for joint evaluations can easily become cumbersome, and care should be taken to keep institutional architecture of the evaluation as simple as possible, especially at the joint steering committee level. Joint evaluations will inevitably 
have transaction costs for the partnering evaluation units, but these can be minimized with appropriate architectures and regular communication. Joint evaluations have the potential to bring together institutions and evaluators with complementary expertise and professional experience, facilitating the creation of an interdisciplinary evaluation team, which is important when evaluating at the nexus of the natural and human systems (Uitto, 2019).

In summary, the experience of the Joint SGP Evaluation supports the findings of earlier studies that the greatest advantages of joint evaluations include the potential for broader scope than single-agency evaluations, increased multidimensionality in the analysis and a single set of coherent messages addressed to multiple partners. The Joint SGP evaluation also illustrates how complementary tools can be used to examine results of a common intervention through different lenses, the environmental, the social and the economic. This is very relevant in the context of the SDGs, where interactions and linkages between goals and targets are increasingly analysed, and the need for integrating different sectoral programmes and to develop cross-sectoral policy is increasingly recognized (e.g. Mainali et al. 2018). Joint evaluations such as the SGP evaluation facilitate the expansion of scope beyond a traditional single sector, bringing together partners with different knowledge and skill sets to foster cross-sectoral analysis, examine trade-offs and highlight synergies and to craft meaningful messages for actors in multiple spheres.

\section{Notes}

1 "Indicator is conceptually clear, has an internationally established methodology and standards are available, and data are regularly produced by countries for at least 50 per cent of countries and of the population in every region where the indicator is relevant." https:// unstats.un.org/sdgs/iaeg-sdgs/tier-classification/.

2 Analysis based on the classification of environment-related indicators by UNEP 2019 and 11 December 2019 updated tier classification https://unstats.un.org/sdgs/iaeg-sdgs/ tier-classification/.

\section{References}

Bodemann-Ostow, N. and Gallego Piñero, R. (2014). Opportunities and challenges of evaluating environment joint programmes. Lessons from the millennium development goal achievement fund. In J.I. Uitto (ed.), Evaluating Environment in International Development. London, Routledge, pp. 256-276.

Carugi, C. (2016). Experiences with Systematic Triangulation at the Global Environment Facility. Evaluation and Program Planning, 55, 55-66.

Carugi, C. and Bryant, H. (2020). A Joint Evaluation with Lessons for the Sustainable Development Goals Era: The Joint GEF-UNDP Evaluation of the Small Grants Programme. American Journal of Evaluation, 41(2), 182-200.

Elder, M. and Olsen, S.H. (2019). The Design of Environmental Priorities in the SDGs. Global Policy, 10(Supplement 1, 70-81. 
Feinstein, O. and Ingram, G.K. (2003). Lessons Learned from World Bank Experiences in Joint Evaluation. Room Document No. 3. Paris: Development Assistance Committee Working Party on Aid Evaluation.

GEF IEO \& UNDP IEO (2008) Joint Evaluation of the Small Grants Programme. Evaluation Report No. 39. Washington, DC: GEF Independent Evaluation Office.

GEF IEO and UNDP IEO. (2016). Joint GEF-UNDP Evaluation of the Small Grants Programme. Evaluation Report No. 97. Washington, DC: GEF Independent Evaluation Office.

GEF IEO and UNDP IEO. (2020). Third Joint GEF-UNDP Small Grants Programme Evaluation, Approach Paper, Carilo.

Mainali, B., Luukkanen, J., Silveira, S., and Kaivo-oja, J. (2018). Evaluating Synergies and Trade-Offs Among Sustainable Development Goals (SDGs): Explorative Analyses of Development Paths in South Asia and Sub-Saharan Africa. Sustainability, 10, 815.

OECD-DAC. (1998). Annual Report by the Chair of the DAC Working Party on Evaluation. $D C D / D A C / E V(99) 1$. Paris: Organization for Economic Co-operation and Development - Development Assistance Committee.

OECD-DAC. (2005). Joint Evaluations: Recent Experiences, Lessons Learned and Options for the Future. DAC Evaluation Network Working Paper. Paris: Organization for Economic Co-operation and Development.

OECD-DAC. (2013). The DAC Network on Development Evaluation - 30 years of strengthening learning in development. Paris: Organization for Economic Co-operation and Development - Development Assistance Committee.

OECD-DAC. (n.d.). Effective Practices in Conducting a Multi-Donor Evaluation. Paris: Organization for Economic Co-operation and Development - Development Assistance Committee.

Rowe, A. (2019). Sustainability-Ready Evaluation: A Call to Action. In G. Julnes (Ed.), Evaluating Sustainability: Evaluative Support for Managing Processes in the Public Interest. New Directions for Evaluation, 162, 29-48.

Swedish Agency for Development Evaluation (SADEV). (2008). Challenges, Opportunities and Approaches for Increasing Joint Donor Programming of Evaluations. SADEV Report 2008:8. Karlstad: SADEV.

Uitto, J.I. (2016). The Environment-poverty Nexus in Evaluation: Implications for the Sustainable Development Goals. Global Policy, 7(3), 441-447.

Uitto, J. I. (2019). Sustainable development evaluation: Understanding the nexus of natural and human systems. In G. Julnes (Ed.), Evaluating Sustainability: Evaluative Support for Managing Processes in the Public Interest. New Directions for Evaluation, 162, 49-67.

United Nations Economic and Social Council. (2015). Thematic evaluation of monitoring and evaluation for the Millennium Development Goals: lessons learned for the post-2015 era. E/ AC. 51.2015/3. 18 March 2015.

United Nations Environment Programme (UNEP). (2019). Measuring progress: Towards achieving the environmental dimension of the SDGs. Nairobi: United Nations Environment Programme.

UN General Assembly. (2006). Note by the Secretary-General transmitting report of the HighLevel Panel on UN System-wide Coherence in the Areas of Development, Humanitarian Assistance and the Environment. A/61/583. 20 November 2006.

UN General Assembly. (2013). Resolution adopted by the General Assembly on 21 2012.A/ RES/67/226. 22 January 2013.

UN General Assembly. (2015). Transforming our world: the 2030 Agenda for Sustainable Development,A/RES/70/1.21 October 2015. 
United Nations General Assembly Economic and Social Council. (2019). Implementation of General Assembly resolution 71/243 on the quadrennial comprehensive policy review of operational activities for development of the United Nations system: funding compact, A/74/73/Add.1 - E/2019/14/Add.1 2019. 2 April 2019.

UN General Assembly Economic and Social Council. (2020). Report of the Secretary General, Implementation of General Assembly resolution 71/243 on the quadrennial comprehensive policy review of operational activities for development of the United Nations System (QCPR), A/75/x-E/2020/7.24 April 2020 (advance unedited version)

United Nations Development Group (UNDG). (2014). Guidance Note on Joint Programmes, New York" UN Development Operations Coordination Office.

UNEG. (2014). Resource pack for joint evaluations. New York: United Nations Evaluation Group. 